\title{
An experimental study of paternal behavior in red-winged blackbirds
}

\author{
Linda A. Whittingham \\ Museum of Zoology and Department of Biology, The University of Michigan, Ann Arbor, Michigan, MI-48109, USA
}

Received November 4, 1988 / Accepted March 13, 1989

\begin{abstract}
Summary. The effect of brood size and female nesting status on male parental behavior was investigated in red-winged blackbirds Agelaius phoeniceus using brood size manipulation experiments. Male redwings allocated parental effort on the basis of brood size and nestling age. Males began assisting females only at nests with at least three offspring older than three days. Female nesting status had no singificant influence on male parental care. When females were unable to meet a brood's demand for food, males assisted females with nestling feeding. Females did not reduce the amount of food delivered to nestlings when males assisted. The amount of food brought to nestlings by the male was additional to the amount of food provided by the female. Male assistance increased fledgling success. When female provisioning was sufficient to meet a brood's demand for food males did not assist. The value of male parental care varied inversely with the ability of the female to meet nestling food demands. The ability of unassisted females to provide sufficient food and to raise a brood of nestlings successfully appeared to be influenced by resource abundance.
\end{abstract}

\section{Introduction}

Polygynous males may provide several forms of parental care. Males can provide a suitable nesting and/or foraging territory. Also, males can defend offspring against predators. These two forms of paternal care can be performed simultaneously for more than one female with little diminuation in effectiveness (Altmann et al. 1977). However, males can also participate in the feeding of nes-

Offprint requests to: Department of Biology, Queen's University, Kingston K7L 3N6, Canada tlings and fledglings. Nestling feeding is less common and more variable among males with polygynous mating systems than in monogamous species (Patterson et al. 1980).

Red-winged blackbirds (Agelaius phoeniceus) are territorial and polygynous (Allen 1914). The breeding range extends from east-central Alaska south to northern Costa Rica, and from the Atlantic to the Pacific (AOU Checklist 1983). Clutch size ranges from two to five but clutches of three and four are most common (Beer and Tibbits 1950; Orians 1980). Earlier clutches tend to be larger than later clutches (Orians 1980). Females feed the young throughout the 12 day nestling period from hatching to fledging. Males occasionally feed nestlings but do not begin until 4 days after hatching (Patterson 1979). Redwing males rarely feed nestlings in western populations of Washington and California (Orians 1961; Payne 1969). In contrast, parental care by some redwing males has been documented in Indiana (Patterson 1979), New York (Yasukawa and Searcy 1982), Ontario (Muldal et al. 1986), and Michigan (Fiala 1979). Paternal care in feeding nestlings has been described as variable, with males preferring to assist at the nests of primary females (Patterson 1979; Yasukawa and Searcy 1982; Muldal et al. 1986).

Males should invest in parental effort when it will positively affect their reproductive success. At least two factors other than female nesting status may influence redwing male parental investment. First, male fitness gains will depend on the ability of males to contribute to offspring survivorship beyond that which the female is already capable of achieving. If one parent can effectively contribute to offspring survival but two parents are only marginally more effective, uniparental care will be favored (Armstrong 1955; Lack 1968). Therefore, male parental care will be favored when there is 
a larger number of nestlings than the female can raise alone. The abundance of food for nestlings may determine the ability of the female to raise offspring unassisted. Allocating paternal care only on the basis of female nesting priority may result in males assisting at nests where the female alone is able to supply sufficient food to nestlings, and male care will not positively influence male reproductive success. Fluctuating resource levels may result in females at different nesting positions requiring male assistance to meet the nestling's demand for food. Second, males will receive greater fitness returns by investing in older nestlings which in turn have a higher reproductive value (Fisher 1958). Males may delay parental investment until the brood is older.

Various correlations between male parental behavior and female nesting status in redwings have been documented. Patterson (1979) and Yasukawa and Searcy (1982) found that males mainly feed young at nests of primary females. However, Muldal et al. (1986) found that male redwings most often assist at the nests of secondary females and less frequently at nests of primary and tertiary females. These results indicate that its not clear how male redwings are influenced by female nesting status.

I designed field experiments to test two alternative hypotheses concerning factors that influence male parental investment in redwings. To examine whether the nesting status of the female influences patterns of paternal investment I tested the following predictions: (1) The primary female will receive male assistance more frequently than later nesting females. (2) The primary female will continue to receive male assistance when the brood size is reduced.

Alternatively, males may invest in parental care in response to brood demand for food. The ability of the female to raise young alone may vary with the brood size and age of nestlings, and resource availability. To examine whether brood size influences male investment in parental care I tested the following predictions: (1) Females of any status with experimentally enlarged broods will receive assistance more frequently than other females. (2) Secondary females will be helped preferentially when their brood size is increased and the brood size of the primary female is reduced.

\section{Methods}

This study was conducted during the 1986 and 1987 breeding seasons at the E.S. George Reserve, Livingston County, Michigan. I studied redwings in 1986 on Southwest marsh and in
1987 on Southwest and Big Cattail marshes. Both marshes are surrounded by a deciduous oak forest. The aquatic vegetation consisted mostly of cattail, Typha latifolia. I captured individual birds with mist nets and with traps baited with cracked corn and millet. Birds were banded with USFWS bands, and each bird was given a unique combination of colored plastic leg bands. Twenty-one males and 17 females were color-banded in 1986. Thirteen males and 16 females were color-banded in 1987. All males and approximately half of the females were color banded in each year.

I plotted male territories on maps of the study marshes by recording movements of individual males and noting locations of boundary displays (Orians and Christman 1968). Nests could be unambiguously assigned to a specific male's territory. I observed females for nest-building activities and searched marshes throughout the breeding season to locate nests. Nearly all nests were found during the egg-laying or incubation phase. Of 56 nests used in the data analysis, 21 were found during egg-laying, 32 were found as completed clutches during incubation and 3 nests were found when young had recently hatched. I checked nests every two days during the nestling period until young fledged, or until the nest was destroyed by predation.

Female status was defined by the hatching sequence of nests (nest status) within a male's territory. The female tending the first nest where young hatched was defined as the primary female, the female tending the second nest where young hatched was defined as the secondary female and so on. Many primary and secondary females were color-banded and predation of early nests was low. In 1987 there was no predation throughout the breeding season. In 1986 only four nests of 20 primary females failed due to predation. Three of these females did not renest on the study marshes. One female renested monogamously on the same territory. Therefore, nest status represents female status.

I observed parental behavior at control nests and at nests where brood size was experimentally altered. Nests were observed for one hour periods to quantify the rate of food delivery to nestlings by adult males and females. Observations were recorded on a cassette recorder and later transcribed. Feeding rate was recorded as number of deliveries per hour at each nest. Most observation periods were conducted betwen 0600 and 1200 noon, on nestling days $2,4,6$, and 8 (day 0 represents hatching). Each nest was examined following the observation period to document the number of young present.

\section{Experimental manipulation of brood size}

I altered brood size to influence the demand for food by nestlings (Patterson et al. 1980; Gori 1984; Boyce and Perrins 1987; Hegner and Wingfield 1987). Each experimental nest was observed on day 4 and again on day 5 prior to brood-size manipulation to establish the presence or absence of male assistance with nestling feeding. Brood-size manipulation experiments were performed late on nestling day 5 .

Three types of brood size manipulation experiments were done: (1) Brood size was increased by the addition of two nestlings at nests with three young where the male was not assisting the female with nestling feeding ( $n=5$ males and 5 nests). (2) Brood size was reduced by removing two nestlings at nests with three or four young where the male was assisting with nestling feeding ( $n=5$ males and 5 nests). (3) Simultaneous increase and decrease experiments involved two males that each had two nests on their territory which were approximately one day asynchronous in hatching. Each male was feeding nestlings at the primary nest with four nestlings and not assisting feeding nestlings at the secondary nest with three nestlings. The brood 
size of the primary female's nest was reduced by removing two nestlings, and the brood of the secondary female's nest was increased by the addition of two nestlings. Nestlings added to broods were identical in age to their foster siblings. Male parental behavior was observed at all experimental nests on nestling day 6 and 8 (day 0 represents hatching) following the brood-size manipulation on nestling day 5 .

\section{Female age}

Primary females may be preferentially assisted by males because they are older, more experienced breeders than later nesting females (Patterson 1979). Female throat and epaulet color were used as a criterion of age. Females with color are generally second year or older breeders while females lacking color are almost certainly first year breeders (Payne 1969; Crawford 1977). I observed each female for four to five hours during the nesting period, and color was scored as present or absent. In addition, eight to ten females were captured by mist net each year and the extent of red color in the feathers was associated with the conspicuousness of color in the field. It was not difficult to observe a female within five meters when I was approaching the nest. There was an extremely close correspondence between judgement of epaulet color in the field and the color of a captured birc.

\section{Data analysis}

I tested five independent variables (nestling number, nestling age, female feeding rate, nest status and hatchday) using probit analysis (Aldrich and Nelson 1987) to determine their influence on the parental behavior of a territorial male (Unversity of Michigan MIDAS Statistical Program). Nestling number indicated brood size, nestling age was measured in days post-hatching, hatchday represented the day of the breeding season the first egg of a nest hatched, where 1 May was day 1 , female feeding rate represented the number of food deliveries per nest per hour, and nest status indicated the chronological order of the nest on the territory.

I used male participation in feeding nestlings as a criterion of parental care. The probit model is useful when the dependent variable is categorical rather than continuous. Male investment in nestling feeding is expressed as a categorical (no/yes) variable. The probability of response by the male is a non-linear function of the independent variables. This contrasts with leastsquares regression which assumes that the magnitude of the response by the dependent variable is a linear function of the independent variables.

Probit analysis uses the cumulative normal (Gaussian) distribution function to estimate the relationship between a group of binary or ordinal covariate predictors (the independent variables) and a categorical outcome (dependent) variable. The ratio of a probit coefficient to its standard error is approximately z-distributed. Data collected from 56 nests, on 4 days of each nestling period, were included in the analysis.

Comparative statistics on feeding rate and fledgling success data were made by Student t-tests, and significance was designated at the 0.05 level.

\section{Results}

Brood size manipulation experiments

Males responded to the brood size manipulation experiments in 1986 as predicted by the brood size hypothesis. At nests where males $(n=5)$ were not feeding nestlings and brood size was increased, all males began feeding nestlings. At nests where males $(n=5)$ had begun feeding nestlings and brood size was reduced, all males stopped feeding nestlings. Males $(n=2)$ with two nests (hatching $<2$ days apart) terminated feeding at the first nest when brood size was reduced and began feeding at the second nest when brood size was increased. Primary females did not continue to receive assistance when brood size was reduced. All females with supplemented broods received male assistance regardless of nesting status.

In 1987, no males fed nestlings at control nests $(n=21)$, and only brood increase experiments were conducted. At seven nests where brood size was increased from three to five nestlings, two males began assisting females and five males did not assist females. Four of these five females with enlarged broods of five nestlings fledged all five young without male assistance. The other female fledged four of five offspring without male assistance. Of the two females that received male assistance, one female fledged five young and the other female fledged two offspring. The five nests where the male did not assist, hatched early in the season (May), whereas the two nests where males did feed nestlings hatched later in the season (June). Although the male fed at the last nest of the season (experimental), two young starved and only two fledged.

\section{Factors influencing male parental investment}

The probit model for 1986 ( $n=28$ nests) demonstrated that all variables, except nest status, had a significant effect on male parental behavior (Table 1). However, some variables more strongly influenced the probability of male participation than others. Nestling number and nestling age had the greatest positive association with males allocating reproductive effort into nestling feeding. Hatchday and female feeding rate also significantly influenced male behavior, but were less powerful predictors that males fed nestlings than nestling number and nestling age. As hatchday increased (as the breeding season progressed) the tendency for males to feed nestlings also increased. Female feeding rate (deliveries/nest/hour) was negatively associated with the probability that males fed nestlings. As the feeding rate of a female decreased it became more likely that a male fed nestlings. Nest status had no significant positive or negative effect on whether males fed nestlings.

The probit model of 1987 ( $n=28$ nests) demon- 
Table 1. Probit analysis. Each independent variable was tested for its influence on the probability that a male will begin feeding nestlings ( $n=28$ nests in each year)

\begin{tabular}{|c|c|c|c|c|c|c|c|c|}
\hline & \multicolumn{4}{|c|}{1986 Model } & \multicolumn{4}{|c|}{1987 Model } \\
\hline & COEFF & SE & $z$ & $p$ & COEFF & SE & $z$ & $p$ \\
\hline Nestling number & 2.16 & 0.47 & 4.60 & 0.001 & 1.16 & 0.36 & 3.23 & 0.005 \\
\hline Nestling age & 0.89 & 0.21 & 4.28 & 0.001 & 0.25 & 0.12 & 2.04 & 0.05 \\
\hline Hatch day & 0.07 & 0.03 & 2.72 & 0.01 & 0.16 & 0.06 & 2.89 & 0.01 \\
\hline Female feeding rate & -0.14 & 0.06 & -2.49 & 0.05 & -0.02 & 0.07 & -0.34 & NS \\
\hline Nest status & -0.44 & 0.28 & -1.60 & NS & -0.23 & 0.18 & -1.26 & NS \\
\hline
\end{tabular}

NS not significant

strates a similar relationship between the independent variables and the probability that males fed nestlings (Table 1). In descending order of effect, nestling number, hatchday, and nestling age are significant and positively associated with male feeding assistance. In contrast to the 1986 model, female feeding rate was not significantly associated with male feeding assistance in 1987. As in 1986, nest status had no significant effect on male parental behavior.

\section{Male feeding and nest status}

During the 1986 breeding season, the number of nesting females per male territory varied from one to four. Nesting was asynchronous and the overlap of nestling periods between two nests (either primary and secondary or secondary and tertiary) was not greater than two days. Males fed at primary, secondary and tertiary control nests. Both quaternary nests were experimental nests. Considering only control nests; six of ten primary nests received male assistance, while three of four secondary nests received male assistance and two of three tertiary nests received male assistance. One male assisted feeding nestlings at all three nests on his territory. No males with more than one nest fed only at the primary nest. Experiments involving the manipulation of brood size, both increase and decrease, were made on primary, secondary, tertiary and quaternary nests. Regardless of nest status, males fed only at nests (both experimental and control) where three to four nestlings were present on or following nestling day 4 .

During the 1987 breeding season, the number of nesting females per male territory ranged from three to nine. Males did not assist feeding nestlings at any control nests. Brood size increase experiments were conducted on seven nests. Experimental nests consisted of four primary nests, one secondary nest, two quaternary nests and one nest which was ninth in status on a territory. Males assisted at one quaternary and the ninth position experimental nests.

\section{Fledgling success}

In 1986 eight control nests that received male assistance fledged offspring, while six nests where the female alone fed nestlings fledged young. Maleassisted nests fledged an average of $2.0( \pm 0.2)$ offspring per nest and unassisted females fledged an average of $1.5( \pm 0.3)$ young per nest. Fledgling success at male-assisted and unassisted nests was not significantly different $(t=1.17, d f=12, P>$ 0.1 ), although male-assisted nests produced $33 \%$ more offspring on average.

All females were unassisted at control nests in $1987(n=21)$. At these nests unassisted females fledged an average of $2.6( \pm 0.3)$ offspring.

\section{Ability of unassisted females to raise young}

Average clutch size was $3.65( \pm 0.1)$ in 1986 and $3.70( \pm 0.1)$ in 1987 . In 1986 hatching success was $97 \%$ while in $1987,90 \%$ of eggs hatched successfully. Most nests had three or four young at hatching and at day 4 of age, however, subsequent survival during the nestling period differed dramatically between years. In 1986, no unassisted females raised four nestlings beyond day 4 . Only one female successfully raised three nestlings to day 6 , and subsequently fledged two. In contrast, unassisted females in 1987 were able to raise and fledge more offspring. Of 21 control nests, five unassisted females fledged four offspring from broods where four hatched, two unassisted females fledged three offspring from broods of four, and seven unassisted females fledged three offspring from broods of three. Unassisted females in 1987 fledged significantly more young than unassisted females in 1986 $(t=-1.97, d f=25, P<0.05)$. 
Table 2. Comparisons of feeding rates in 1986 (mean number of deliveries $/$ nest $/ \mathrm{h} \pm \mathrm{SE}$ )

\begin{tabular}{llrr}
\hline & \multicolumn{4}{l}{ Brood size $(n)$} \\
\cline { 2 - 4 } & $2(6)$ & \multicolumn{1}{l}{$3(11)$} & \multicolumn{1}{c}{$4(12)$} \\
\hline Female with assistance $^{\mathrm{a}}$ & $\mathrm{NA}$ & $10.4 \pm 0.8$ & $10.8 \pm 1.1$ \\
Female without assistance 6.8 \pm 1.5 & $9.1 \pm 0.8$ & $8.1 \pm 0.9$ \\
Male & $\mathrm{NA}$ & $5.4 \pm 0.5$ & $6.3 \pm 0.7$ \\
Male/female combined $^{\mathrm{b}}$ & $\mathrm{NA}$ & $15.8 \pm 0.9$ & $17.1 \pm 1.5$ \\
\hline
\end{tabular}

$\mathrm{NA}=$ no females without assistance raised 4 offspring to day 6. no males assisted females with less than 3 nestings

a comparison of feeding rates for females with and without male assistance, NS

${ }^{b}$ comparison of feeding rates of females without assistance and male/female combined feeding rate, $P<0.025$

NS not significant

\section{Feeding rates at control nests}

Feeding rates between females with and without assistance were not significantly different in 1986 (Table 2). In addition, feeding rates of females were not significantly different for different brood sizes. However, there was a tendency for females with broods of two nestlings to feed at a lower rate than females with three or four nestlings. Males fed nestlings at approximately one-half the rate of females. Therefore, at male-assisted nests nestlings received more food than nestlings where the female was feeding alone. The combined male and female feeding rates were significantly greater than the feeding rates for females without assistance (Table 2).

Females raising nestlings alone fed at a significantly higher rate in 1987 than unassisted females in 1986 (Table 3). Feeding rates were not significantly different between unassisted females in 1987 and combined male and female rates in 1986 (Table 3).

\section{Female age}

Two-way contingency tables were used to test the relationship between female age and (1) the number of nestlings surviving to day 4 (arranged in two categories: $\leq 2$ nestlings, and $\geq 3$ nestlings), and (2) whether males assisted older females more frequently. There was no association between female age and nestling survival to day $4\left(X^{2}=0.043\right.$, $d f=1, P=0.835$ ). Thirteen of 16 older females, and seven of nine younger females, raised three or four nestlings to day 4 of age. Also, there was no association between female age and male assistance
Table 3. Comparisons of feeding rates of unassisted females between study years and between 1987 unassisted females and male/female combined 1986 (mean number of deliveries/nest/ $\mathrm{h} \pm \mathrm{SE}$ )

\begin{tabular}{lcc}
\hline & \multicolumn{2}{c}{ Brood size } \\
\cline { 2 - 3 } & 3 & 4 \\
\hline Unassisted females $^{\mathrm{a}}$ & $9.1 \pm 0.8$ & $8.1 \pm 0.9$ \\
1986 & $n=21$ & $n=12$ \\
Unassisted females $_{1987}$ & $14.8 \pm 0.7$ & $15.5 \pm 0.7$ \\
Male/female & $n=33$ & $n=21$ \\
combined $1986^{\mathrm{b}}$ & $15.8 \pm 0.9$ & $17.1 \pm 1.5$ \\
& $n=11$ & $n=12$ \\
\hline
\end{tabular}

${ }^{a}$ feeding rates between 1986 and 1987 unassisted females are significantly different, $P<0.005$

${ }^{b}$ feeding rates between unassisted females 1987 and male/female combined 1986 are not significantly different

$\left(X^{2}=0.001, d f=1, P=0.973\right)$. Nine of 16 older females, and five of nine younger females, received male assistance on or following day 4 of the nesting period.

\section{Discussion}

\section{Males respond to brood size}

Brood size and female nesting status were proposed as alternative hypotheses for the basis of male parental investment. The behavior of each male, tested by experimental brood size manipulations, changed as predicted by the brood size hypothesis. These results provide compelling evidence that males determine parental investment by evaluating brood size and do not respond exclusively to female nesting status.

Male parental care was also significantly influenced by nestling age. Males delayed feeding nestlings until day 4 of the nestling period. A similar delay in male parental care was observed by Patterson (1979) and Muldal et al. (1986). Males may be preferentially investing in older nestlings because they have higher reproductive value. In addition, this portion of the nestling period may represent an increase in the brood demand for food. In redwing nestlings thermoregulation is brought under individual physiological control at four or five days of age and is associated with higher metabolic costs (Hill and Beaver 1982). Increased metabolic costs may be associated with increased nestling demand for food and the necessity for male assistance when females alone cannot provide sufficient resources. 
The number of young present in the nest on day 4 varied, and because males do not assist with nestling feeding until day 4 , the number of nestlings depended on the quality of parental care provided by the female. Older or earlier nesting females were not preferentially assisted with nestling feeding by males. However, the ability of females to raise three or four nestlings to day 4 may depend on female body condition at time of breeding (Slagsvold and Lifjeld 1988).

\section{Variability between and within breeding seasons}

Because redwing parents feed mainly insects to their young (Orians 1961; Wilson 1978), and insect abundance is dependent on weather (Orians 1980), I expect food abundance and hence the ability of an unassisted female to meet a brood's demand for food to vary between years and within a breeding season. Gori (1984) examined the ability of female yellow-headed blackbirds to raise young without male assistance in productive and unproductive marshes (assessed by odonate emergence). He found that unassisted females raised more offspring in productive marshes. Lenington (1980) suggested an association between variation in food abundance between territories and female reproductive success. Variation in the abundance of nestling food between and within years, among marshes and possibly between territories, may significantly affect fledgling success.

Male parental effort differed between years. The ability of unassisted females to provide adequate food to raise a brood of three or four nestlings varied between years and appears to have affected the necessity of male assistance with nestling feeding. The ability of the male to contribute to offspring survival beyond what the female is capable of achieving was examined by Gowaty (1983) by experimentally removing males of monogamously breeding pairs of eastern bluebirds ( $\mathrm{Sia}$ lia sialis). Paired and experimentally deserted females had similar fledgling success, however, this study was conducted only in one year and perhaps that was a year when nestling food was particularly abundant. Differences in the fledgling success of redwings between years suggest that the greater feeding rate achieved by unassisted females during 1987 was sufficient to meet the food requirements of larger broods while the feeding rate of unassisted females in 1986 was not. Similarly, Strehl and White (1986) found increased fledgling success and nestling survival caused by decreased starvation during a period of insect abundance. Food resources for redwing nestlings were apparently more abundant during most of the 1987 breeding season than in 1986. The ability of unassisted females to raise nestlings appears to be influenced by resource abundance and consequently affects the importance of male parental care to fledgling success.

Resource availability also varied substantially within the 1987 breeding season. The ability of unassisted females to raise experimental and control broods declined later in the 1987 breeding season. Consequently, males were not able to increase fledgling success through parental care in feeding nestlings early (May) in 1987. In contrast, males assisted at experimentally enlarged later (June) broods which apparently required more food than an unassisted female could supply. A shift in resource abundance was also indicated by the physical condition of the nestlings. The average mass of day 4 nestlings in June was approximately 6 grams less than day 4 nestlings raised earlier during the season in May. Day 4 nestlings in June were similar in size to younger, day 2 or 3 nestlings in May. June nestlings generally appeared undernourished. Most nestlings starved in the last five nests to hatch in 1987. Only zero or one nestling fledged from each of the last five nests. Robertson (1973) and Gori (1984) also found increased starvation of nestlings toward the end of the breeding season.

\section{Female nesting status}

Female or nest status did not significantly affect the probability that a male would assist with nestling feeding. Fluctuation of resource levels within a breeding season at different study marshes may account for the observations that males most often assist primary females (Patterson 1979) in one study area and secondary females (Muldal et al. 1986) at a different location. Tertiary or later nesting females may appear to receive male assistance less often if food availability significantly declines later in the breeding season and these females are unable to raise at least three nestlings to day 4 .

Nesting synchrony may influence the importance of nest status to the male. Most females in 1986 nested asynchronously such that nestling periods only partially overlapped. Therefore, not all nests potentially required male assistance simultaneously. In 1987, nesting was much more synchronous, however, male assistance was not necessary to provide sufficient resources to nestlings. In years 
or marshes with low nestling food availability, asynchronous nesting may favor secondary, and possibly later nesting females receiving male assistance. The extent of female nesting synchrony may be associated with the necessity of male parental care.

The ability of the female to raise a brood alone apparently determines the value of parental care to the male. In some years male redwings appear to be able to positively influence their reproductive success by investing in parental care. Fledgling success increased when males assisted. Muldal et al. (1986) found a significant difference in fledgling success between male-assisted and unassisted nests. The reproductive success of a polygynous male redwing over the breeding season may be the result of a trade-off between mating effort and parental effort (Trivers 1972). Consequently there may be a cost to parental effort. Because brood-size manipulation experiments were conducted on many different males and most control males fed at at least one nest, I cannot make a comparison between female breeding-group size and paternal care. Parental activities may also affect male physical condition. Nur (1984) found that increased frequency of feeding nestlings was associated with decreased female weight in blue tits (Parus caeruleus), but there was no relationship between feeding frequency and male weight.

Results of field experiments and behavioral observations of redwings in this study concur on four points: (1) Males invest when the female alone can not meet a brood's demand for food. (2) When the female does require assistance, the male's participation is based on the age and number of nestlings. (3) Males assist only at nests when 3 or 4 young at least 4 days of age are present. (4) Following the above criteria, males assist females regardless of nest status, or prior breeding experience.

This study identifies brood size as an important factor in male parental care. Experimental brood size manipulations demonstrated that parental care by the polygynous redwing male was flexible and varied in response to brood size and nestling age. The results illustrate the conditions under which biparental and uniparental care may be favored in a polygynous species and accounts for the observed variation in redwing parental care behaviour.

Acknowledgments. I thank R.B. Payne, R.J. Roberston, K. Yasukawa, B.J. Crespi, K.F. Conrad and H.L. Gibbs for constructive criticism of the manuscript. The University of Michigan
Museum of Zoology provided research facilities at the E.S. George Reserve. H. Berk assisted me in the field in 1987. I thank the University of Michigan Statistical Research Lab. This research was supported by a University of Michigan Block Grant, a University of Michigan Museum of Zoology George Reserve Fellowship, and a Sigma Xi Grant-in-Aid of Research.

\section{References}

Aldrich JH, Nelson FD (1987) Linear probability, logit, and probit models. Sage University Paper series on Quantitative Applications in the Social Sciences, series no. 07-001. Sage Publications, Beverly Hills London

Allen AA (1914) The red-winged blackbird: A study in the ecology of a cattail marsh. Proc Linn Soc NY 24-25:43-128

Altmann SA, Wagner SS, Lenington S (1977) Two models for the evolution of polygyny. Behav Ecol Sociobiol 2:397-410

American Ornithologists' Union (1983) Check-list of North American birds. 6th edn. Allen Press, Lawrence

Armstrong EA (1955) The wren. Collin, London

Beer JR, Tibbits D (1950) Nesting behavior of the red-winged blackbird. Flicker 22:61-77

Boyce MS, Perrins CM (1987) Optimizing great tit clutch size in a fluctuating environment. Ecology $68: 142-153$

Crawford RD (1977) Breeding biology of year-old and older female red-winged and yellow-headed blackbirds. Wilson Bull 89:73-80

Fiala KL (1979) Natural selection and the sex ratio in the redwinged blackbird. $\mathrm{PhD}$ thesis, University of Michigan

Fisher RA (1958) The genetical theory of natural selection. 2nd edn. Dover Publications, New York

Gori DF (1984) Evolution of paternal care patterns and coloniality in yellow-headed blackbirds (Xanthocephalus xanthocephalus). PhD thesis, University of Arizona

Gowaty PA (1983) Male parental care and apparent monogamy among eastern bluebirds (Sialia sialis). Am Nat $121: 149-157$

Hegner RE, Wingfield JC (1987) Effects of brood-size manipulations on parental investment, breeding success, and reproductive endocrinology of house sparrows. Auk 104:470-486

Hill R, Beaver DL (1982) Inertial thermostability and thermoregulation in broods of redwing blackbirds. Physiol Zool $55: 250-266$

Lack D (1968) Ecological Adaptations for Breeding Birds. Methuen, London

Lenington S (1980) Female choice and polygyny in redwinged blackbirds. Anim Behav 28:347-361

Muldal AM, Moffatt JD, Robertson RJ (1986) Parental care of nestlings by male redwinged blackbirds. Behav Ecol Sociobiol 19:105-114

Nur N (1984) Feeding frequencies of nestling blue tits (Parus caeruleus): costs, benefits and a model of optimal feeding frequency. Oecologia 65:125-137

Orians GH (1961) The ecology of blackbird (Agelaius) social systems. Ecolog Monog 31:285-312

Orians GH (1980) Some Adaptations of Marsh-nesting Blackbirds. Princeton Press, Princeton University

Orians GH, Christman GM (1968) A comparative study of the behaviour of redwinged, tricolored, and yellow-headed blackbirds. University of California Publications in Zoology $84: 1-81$

Patterson CB (1979) Relative parental investment in the redwinged blackbird. Ph.D. thesis, Indiana University

Patterson CB, Erckmann WJ, Orians GH (1980) An experimen- 
tal study of parental investment in male blackbirds. Am Nat 116:757-769

Payne RB (1969) Breeding seasons and reproductive physiology of tricolored blackbirds and redwinged blackbirds. Univ Calif Publ Zool 90:1-137

Robertson RJ (1973) Optimal niche space of the red-winged blackbird III. Growth rate and food of nestlings in marsh and upland habitat. Wilson Bull 85:209-222

Slagsvold T, Lifjeld JT (1988) Ultimate adjustment of clutch size to parental feeding capacity in a passerine bird. Ecology $69: 1918-1922$
Strehl CE, White J (1986) Effects of superabundant food on breeding success and behaviour of the red-winged blackbird. Oecologia 70:178-186

Trivers RL (1972) Parental investment and sexual selection. In: Campbell B (ed) Sexual selection and the descent of man. Aldine, Chicago, pp 136-179

Wilson SW (1978) Food size, food type, and foraging sites of red-winged blackbirds. Wilson Bull 90:511-520

Yasukawa K, Searcy WA (1982) Aggression in female redwinged blackbirds: a strategy to ensure male parental investment. Behav Ecol Sociobiol 11:13-17 